\title{
A survey of undergraduate teaching of clinical neurology in the United Kingdom 1990
}

\section{M S Wilkinson}

\section{Discussion}

The cornerstone of teaching clinical neurology to undergraduates is an attachment to the department of neurology. There are still two schools in which no medical students have an attachment to the neurological department, and six schools where only a fraction of the students have such an attachment. Twenty of the 28 schools offer attachments to all students, and this is the same state of affairs that existed in 1979. The presence or absence of this crucial platform for teaching strongly relates to the student:teacher ratio. In schools where the ratio was greater than $28: 1$, clinical attachments were not provided for all students.

The attachment works best when shared with neurosurgery, and not so well when shared with other unrelated specialist subjects. Attachment of the students to the Regional Clinical Neurosciences Unit, where they may receive integrated teaching from neurologists, neurosurgeons, neuroradiologists, clinical neurophysiologists and neuropathologists, is the optimal arrangement. The same conclusion emerged from the survey of 1979 .

It is very difficult to teach neurology to clinical students in an attachment of less than four weeks. This fact probably underlies the current failure to achieve the learning objectives of the clinical attachment in a substantial number of schools, even where these objectives are kept under constant review. It takes time for a student to become proficient in the performance of the neurological examination, and to see enough patients with the common neurological conditions, emergencies and disabilities. Even though clinically based teaching, at the bedside and in the outpatient clinic is strongly favoured, and even though overemphasis on lectures is regarded as unsatisfactory, there is still a considerable amount of lecturing to clinical medical students by neurologists.

Clearly there needs to be a sufficient number of consultant neurologists to provide the teaching of neurology to medical students. This survey suggests that when the ratio of clinical student:consultant neurological teacher is greater than 28:1, an adequate and comprehensive teaching provision cannot be given. In the view of the majority, there should be a nominated neurologist in each school with formal responsibility for the students' neurological teaching programme.

It is recognised that this survey is not completely comprehensive. It has concentrated upon the provision of neurological instruction 


\section{CLINICAL ATTACHMENT-BASIC FACTS}

Is a clinical attachment to the neurology department mandatory for all students?

If it is not, what percentage of students do have a clinical neurological attachment?

Duration of attachment in weeks? full time attachments $(n=11)$ part time attachments $(n=15)$

How many students in the student group attached to the neurological department at any one time?

How many students in the student group at a typical ward-based teaching session?

How many students in the student group at a typical outpatient clinic teaching session, (that is in the company of 1

doctor)?

Is the clinical attachment:

full-time neurology (that is, all neurology or neurology shared only with neurosurgery?)

shared with other specialist subjects including neurosurgery?

shared with other specialist subjects excluding neurosurgery?

If shared with neurosurgery:

is the sharing beneficial for the students?

why? ability to follow cases through

plenty of cases with excellent physical signs exposure to emergencies

what percentage is neurology?

If shared with other subjects:

is the sharing beneficial for the students?

why? students disappear all the time

neurology is not the main focus

what percentage is neurology?

20

$\begin{array}{rrr}80 & 0-70 \\ & 4 & 2-6 \\ 6 & 2-12 \\ 12 & 4-60 \\ 8 & 3-12 \\ & 3 & 1-10\end{array}$

\section{CLINICAL ATTACHMENT-LEARNING OBJECTIVES}

During the attachment, does each student:

learn the technique of neurological examination from a neurologist?

practise his technique of neurological examination on enough patients?

receive a list, or other direct guidance, of the common neurological diseases with which he should become familiar? have adequate exposure to inpatients and outpatients to see examples of the common neurological diseases?

receive a list, or other direct guidance, of the acute neurological emergencies with which he should become familiar? have adequate exposure to patients with acute neurological emergencies?

have adequate exposure to patients with chronic neurological disability?

have the opportunity of being introduced to the concept of team management of patients with chronic neurological disability?

\section{LECTURES GIVEN BY NEUROLOGISTS TO CLINICAL STUDENTS}

Introductory

do they occur?

how many?

to whole class at once?

Comprehensive course of lectures on the common neurological conditions

do they occur?

do they occur?

to whole class at once?

to whole

do they occur?

how many?

to whole class at once?

LARGE-SCALE PATIENT-DEMONSTRATIONS GIVEN BY NEUROLOGISTS TO CLINICAL STUDENTS

That is, a neurologist demonstrating one or more patients to a group of 20 or more clinical students.

do they occur?

how many per year?

number of students attending?

$\mathrm{NB}-$ These sessions are common in schools without an obligatory neurological attachment for all students.

\section{NEUROLOGICAL TEACHING-BEST AND WORST FEATURES}

Please mention any strong features of the teaching in your school

Clinically based, bedside and OPD, teaching

Wide variety of cases, acute and chronic

Joint attachment with neurosurgery

Joint attachment with neurosurgery

Clinical attachment is at the regional unit so the teaching is integrated
Six to eight week attachment gives students a chance to see examples of most conditions

Six to eight week at

Interest of teachers
Consultants heavily involved in the teaching

Please mention any problems with the teaching in your school

Lack of clinical attachment for all/any students

Two to three week's attachment is too short

Insufficient teachers

Too much emphasis on lectures, not enough "hands on"

Clinical attachment shared with unrelated subjects

Geographical separation of teaching from regional unit

No teaching of neurological emergencies

Not

MANPOWER (median results for the 28 United Kingdom medical schools)

Number of Clinical Students per year

Number of Clinical Students per year

Number of National Health Service
involved in neurology teaching

involved in neurology teaching
Number of academic consultant neurologists in the medical school involved in neurology teaching

Number of academic consultant neurologists in the
Clinical student: consultant teacher ratio (130:5)

Clinical student: consultant teacher ratio (130:5)
Is there consultant neurological input into the planning of the clinical curriculum?

Is there consultant neurological input into the planning of the clinical curriculum?
Is there a particular consultant neurologist (National Health Service or Academic) with formal responsibility for

the students' neurological teaching programme?

If yes, is he National Health Service or Academic?

NHS $6 \quad$ Academic 11

If no, should there be?

If all clinical students had a four week full time neurological clinical attachment, are there sufficient neurological consultants to support the teaching programme?

cons
yes
just

just about

no

nowhere near 


\begin{tabular}{|c|c|c|}
\hline \multicolumn{3}{|c|}{ Average student: teacher ratios in relation to the above question } \\
\hline yes & $\mathrm{n}=7$ & ratio $20: 1$ \\
\hline just about & $\mathrm{n}=10$ & ratio $27: 1$ \\
\hline no & $\mathrm{n}=\mathbf{8}$ & ratio 38:1 \\
\hline nowhere near & $\mathbf{n}=\mathbf{3}$ & ratio 54:1 \\
\hline \multicolumn{3}{|c|}{ Average student: teacher ratios in relation to the type of clinical neurological attachment which exists at the moment } \\
\hline full time attachment for all students & & ratio $26: 1$ \\
\hline part time attachment for all students & $(n=9)$ & ratio $28: 1$ \\
\hline part time attachment for some students only & $(\mathrm{n}=6)$ & ratio 44:1 \\
\hline no attachment at all & $(\mathrm{n}=2)$ & ratio $48: 1$ \\
\hline
\end{tabular}

by consultant staff in the neurological specialties at the teaching hospitals. Teaching of neurology by junior staff, by staff in other specialties (for example, general medicine), and by neurologists away from the main teaching sites has not been included. The compliance of the questionnaire respondents was always kept in mind, and the need for a $100 \%$ response rate made it important that the questionnaire was relatively short, concise and easy to complete. Furthermore, the survey has only collected information on the nature and amount of neurological instruction of clinical medical students in the United Kingdom, and has not examined its quality. Direct approach to the students, and a rather complex assessment of neurological knowledge and skills five or 10 years after registration, would be necessary to ascertain the short and long term effects of any individual neurological teaching programme.

I am grateful to Dr P Munro and to Dr R Langton Hewer for their encouragement to carry out this second survey, and to the neurological colleague in each medical school who was kind enough to complete the questionnaire.

1 Wilkinson IMS, Rogers J, Wakeford R. Neurology teaching in UK medical schools. Medical Teacher 1979;1:87-92. 